\title{
In Defense of Multiple Regression: A Renewed Effort to Educate the Public
}

\author{
Joel Snell* \\ Arlington Institute, USA \\ *Corresponding author: Joel Snell, Arlington Institute, USA
}

\section{Introduction}

\section{Social sciences findings shaky}

The reliability of social science studies has been thrown into question, after an attempt to replicate project 21 high profile experiments yielded only 13 successful reproductions. The twoyear research project centered on studies that were published between 2010 and 2015 in highly respected journals Science and Nature..." THE WEEK, September 14, 2018, 20.

\section{Description}

In a working paper entitled "Multiple Regression: Evolution and Analysis" SOCIALVIBES.NET/ Numerous critics indicate that Multiple Regression that emerged in general academia in the "Big Data Days" (early to mid-70's) was basically" junk science." Promoters indicated that the formula was a sign that the soft social sciences had grown closer to the hard sciences. A computer could do the work of numerous clerks, handling portions of a problem back in the 50's and 60's. Now the computer could solve the problem in minutes. However, not all numbers gathered were of the necessary interval level which is needed for the formula.

However, there is overwhelming supportfor Multiple Regression. Numerous articles describe and inadvertently or directly support it. It is not the research strategy Multiple Regression that is at fault, but the quality of the data that is used. The researcher, reviewer, or editor misses the poor quality of the data that is analyzed (false positives.)

It is now more important than ever. From a new book by Andersen [1] approximates that whatever was "normal" deconstructed into chaos around the year 2000 or the turn of the century. This New York Times bestseller is written by a decorated social science writer with numerous books, periodicals, and media reporting suggests that from the Left strategies and research is of poor quality. However, he does not say all is wrong. From the
Right, the Evangelical movement has had overwhelming growth dealing with their own academic appearing studies and Christian published books. Entire stores are devoted to this information. Further, they can partner with large corporations that appear to be destroying the planet. Additionally, out right "fakes news" has become normalized. Again, he does not say all of their information is wrong.

Thus, the average citizen does not know what to believe. However, the least strong points should be noted. Thus, two computations emerge. 1) to make nominal numbers, into interval integers a researcher arbitrarily takes the formula of nominalism and added a zero. (------,2020). Therefore, $0+1=1 / 2=.05$. So, the division of two numbers by 2 makes it an interval number $S$. Troche [2] Multiple regression needs all interval numbers or greater (ratio numbers) to complete the task. In number 2, numerous attempts were made, but two researchers in 1984, found that making an ordinal number into an interval number did not disturb the outcomes Winship C, R. Mare [3] Thus, all numbers used in multiple regressions are treated interval or ratio.

Until a better measure is introduced it would appear to this author that a few strategies can monitor and increase validity. One is to allow lesser measures into manuscripts and the publication "counts" toward tenure. Two, make a transition in the social sciences, that a refereed manuscript found acceptable must then go to a "Replicator." This person has an excellent reputation and is paid or given last authorship on a paper. He then retests the manuscript.

Other strategies include using triangulation where the multiple regressions are also complimented by original observations and exhaustive related literature review. Last, create a longitudinal study (not a panel study) in which descriptive statistics are used to see certain variables are more prevalent than others to "explain" the dependent variable (identity groups and/or demographic groups) 
may also be useful. Further, get the word out to quality periodicals that Multiple Regression works, and that criticism has been helpful to improve the strategy. It is a great story and can also be splintered into small articles sent to national and local distributors. Therefore, mainstream social sciences and related are doing something about this issue [4].

Last invite Replicators to analyze a quality article to discover if there are some false positives that make multiple regressions other than valid. The Replicator should be known to the editor and journal reviewers and must be given attribution with the other writers. Incidentally, the best linear unbiased estimator must be recalculated and the use of forward and path analysis are put aside to avoid multicollinearity, so that stepwise solution is used [5].

\section{Summary and Conclusion}

Although Multiple Regression has lost a great deal of prestige relative to its accuracy, it is worth saving. The author indicates some strategies.

\section{References}

1. Anderson K (2017) Liberals Denying Science. 41, Fantasyland, How America Went Haywire, 500 Year-History, New York: Random House LLC, 376-380.

2. Trochim S (2006) Research Knowledge Base. Social research methods. net/kb/scallik php.

3. Winship C, R Mare (1984) Regress Models with Ordinal Values American Sociological Review 8: 512-515.

4. (2020) Dummy variables in Regression, Stat Trek.com Portions of this article have been taken from an upcoming article of Multiple Regression: Evolution and Analysis. Education, June 2020. A rough draft is in Social Vibes.Net/.

5. Snell Joel (2019) Multiple Regression: Evolution and Analysis, Social vibes.net.

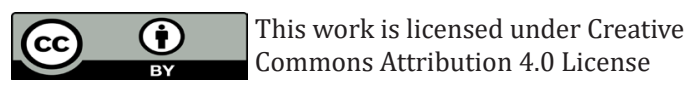

To Submit Your Article Click Here: Submit Article

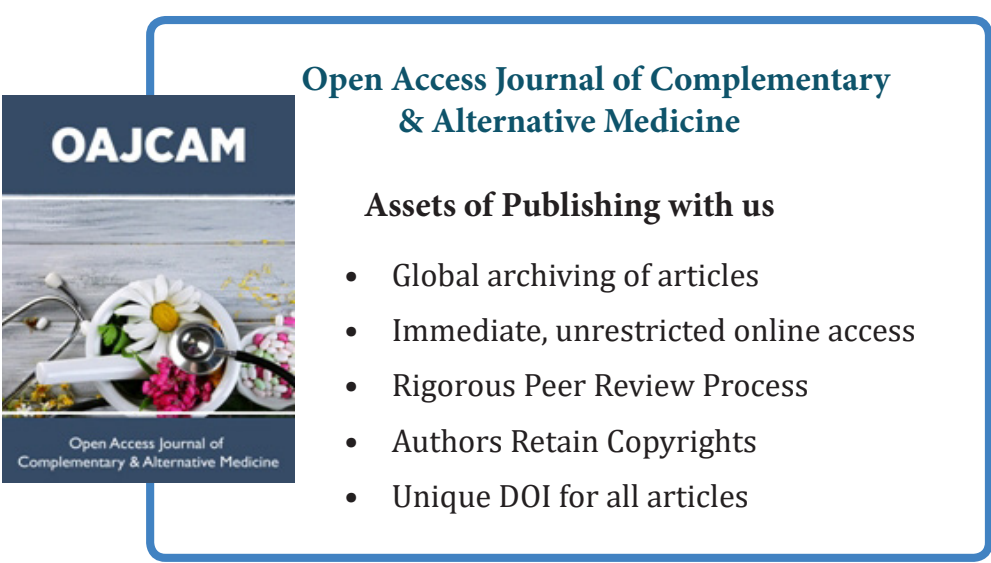

